\title{
Distribution and chemical composition of snow cover of the Sygyktinsky glacier (Kodar Ridge, south eastern Siberia)
}

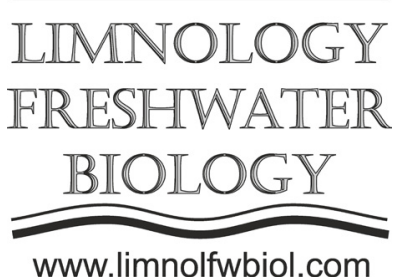

Osipov E.Y.

Limnological Institute, Siberian Branch of the Russian Academy of Sciences, Ulan-Batorskaya Str., 3, Irkutsk, 664033, Russia

ABSTRACT. Snow survey was carried out in the central part of the Sygyktinsky Glacier (Kodar Ridge, south eastern Siberia), and a map of the distribution of snow cover was constructed (average snow thickness was $97 \mathrm{~cm}$ ). Stratigraphy and the chemical composition of the snow cover were studied in a snow pit. It was established that the chemical composition of the snow belongs to the chloride class, ammonium and sodium groups. At the same time, the ionic composition of snow reflects seasonal changes in atmospheric circulation in the region (local continental sources of ions prevail in winter, while the proportion of "marine ions" increases in the spring).

Keywords: Kodar ridge, Sygyktinsky glacier, snow cover, chemical composition

\section{Introduction}

Sygyktinsky glacier, Kodar ridge, South East Siberia, is located in watersheds of the Levaya Sygykta and Syulban rivers. The glacier has two tongues, the northern (glacier No. 5 according to the USSR Glacier Catalog) and the southern (glacier No. 26). The work was carried out in July-August 2019 on glacier No. 5. Glacier 5 has an overall eastern extent, although due to the asymmetry, the surface is more inclined to the southeast. The glacier is fed mainly by avalanches that come in spring from the southeastern and southern slopes. The glacier area is $0.291 \mathrm{~km}^{2}$, the length is $0.758 \mathrm{~km}$, the maximum height is $2670 \mathrm{~m}$, the average height is $2543 \mathrm{~m}$, the average slope is $19^{\circ}$, the average long-term height of the firn line is $2535 \mathrm{~m}$.

\section{Results and discussion}

The distribution of snow cover according to the snow survey performed on July 7 in the central part of the glacier (between points 2 and 4 ) is shown in fig. 1. The thickness of the snow in the investigated area ranged from 50 to $125 \mathrm{~cm}$, average $97 \mathrm{~cm}$. An increase in the thickness of the snow towards the slope zone was revealed (the effect of avalanche accumulation). The snow is loose, moist, with an average density of 0.3-0.4 $\mathrm{kg} \mathrm{m}^{-3}$, with thin layers of infiltration ice. On average, the layer of unmelted snow (at the time of the snow survey) was estimated at $34 \mathrm{~cm}$ of water equivalent.

A snow pit of $1.1 \mathrm{~m}$ deep was dug on the subhorizontal surface of the glacier. The exposed strata is represented by waterlogged firmed snow with an average density of $\mathrm{kg} \mathrm{m}^{-3}$. The upper $5 \mathrm{~cm}$ of the strata are contaminated with a silty material of mineral origin. At a depth of $20 \mathrm{~cm}$, an interlayer of infiltration ice with a thickness of $2 \mathrm{~cm}$ is visible. At the bottom of the pit, porous monolithic ice of infiltration-congelation origin with a density of $0.8 \mathrm{~kg} \mathrm{~m}^{-3}$. An intense melt runoff is observed along the ice base. The structural features of the section make it possible to attribute the snow layer to the accumulation season 2018-2019.

Six samples were taken from the pit for chemical analysis (Fig. 2). In general, in terms of chemical composition, the studied snow (according to the classification of natural waters by Alekin) belongs to the chloride class, ammonium and sodium groups. The total mineralization decreases down the section and, on average, is $0.282 \mathrm{mg} \mathrm{L}^{-1}$. The maximum mineralization is $0.404 \mathrm{mg} \mathrm{L}^{-1}$ (depth $30 \mathrm{~cm}$ ), and the minimum is 0.082 $\mathrm{L}^{-1}$ (depth $90 \mathrm{~cm}$ ). A slight increase in mineralization at a depth of $105 \mathrm{~cm}$ is associated with the infiltration of melt water through the snow column and their repeated freezing at the boundary with the underlying ice. In general, according to the degree of mineralization, the snow cover is weakly mineralized and belongs to ultrafresh waters. All samples are characterized by a weakly acidic reaction ( $\mathrm{pH}$ value is 5.85-6.26, average value is 5.99). Chloride ions predominate in the upper part of the section $(0-30 \mathrm{~cm})$, and nitrate ions in the middle $(50 \mathrm{~cm})$ and lower $(105 \mathrm{~cm})$ parts. An increase in the content of sulfate ion is also observed in the middle part of the section at a depth of $70 \mathrm{~cm}$. Among the cations in the upper part of the section, increased concentrations were found in sodium, potassium and calcium ions, and in the middle part, in ammonium

*Corresponding author.

E-mail address: eduard@lin.irk.ru (E.Y. Osipov) 


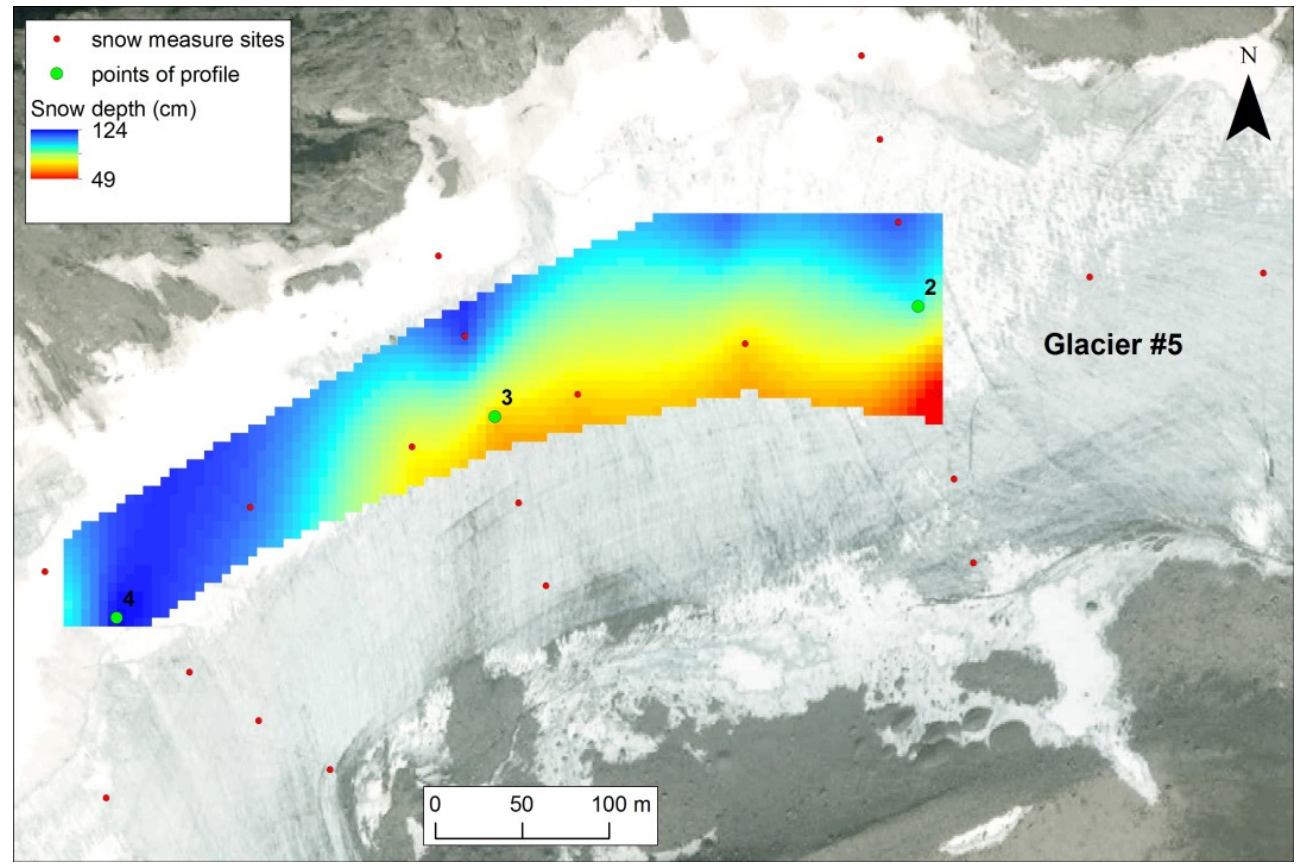

Fig.1. Map of the distribution of the thickness of the snow cover in the central part of the glacier on 07.07.2019 (background is WorldView-2 satellite image dated 11.08.2013)

ions. The coincidence of the maxima of $\mathrm{pH}$ and calcium values at a depth of $30 \mathrm{~cm}$ confirms the presence of a hydrocarbonate ion in the sample.

Sulfates and calcium are predominantly of continental origin. Only in the surface layer of snow $(0-10 \mathrm{~cm})$ the content of «sea» calcium reaches $10 \%$ (in other samples 1-3\%). The maximum content of «marine» sulfate (up to $31 \%$ ) is also observed in the upper part of the section, at a depth of $0-30 \mathrm{~cm}$.

\section{Conclusions}

Thus, the ionic composition of the studied samples reflects the peculiarities of the formation and transformation of the snow cover on the glacier during its accumulation (September-May) and ablation (June-August) under the influence of different-scale atmospheric circulation processes in the region. In winter, under the conditions of the Siberian anticyclone, continental ion sources, mainly of local origin, prevail. In the spring, with an increase in cyclonic activity, the proportion of «sea ions» arriving with solid precipitation increases, while the total mineralization of snow increases in comparison with the underlying horizons. Intense melting on the snow surface at the beginning of the ablation season leads to the infiltration of melt water into the snow, washing out of mobile ions and their accumulation in the underlying infiltrationcongelation ice, which is reflected in changes in ion concentrations along the section.

\section{Acknowledgements}

The work was supported by the Russian Foundation for Basic Research (grant No. 19-05-00668) and by the research projects No. 0345-2019-0006.

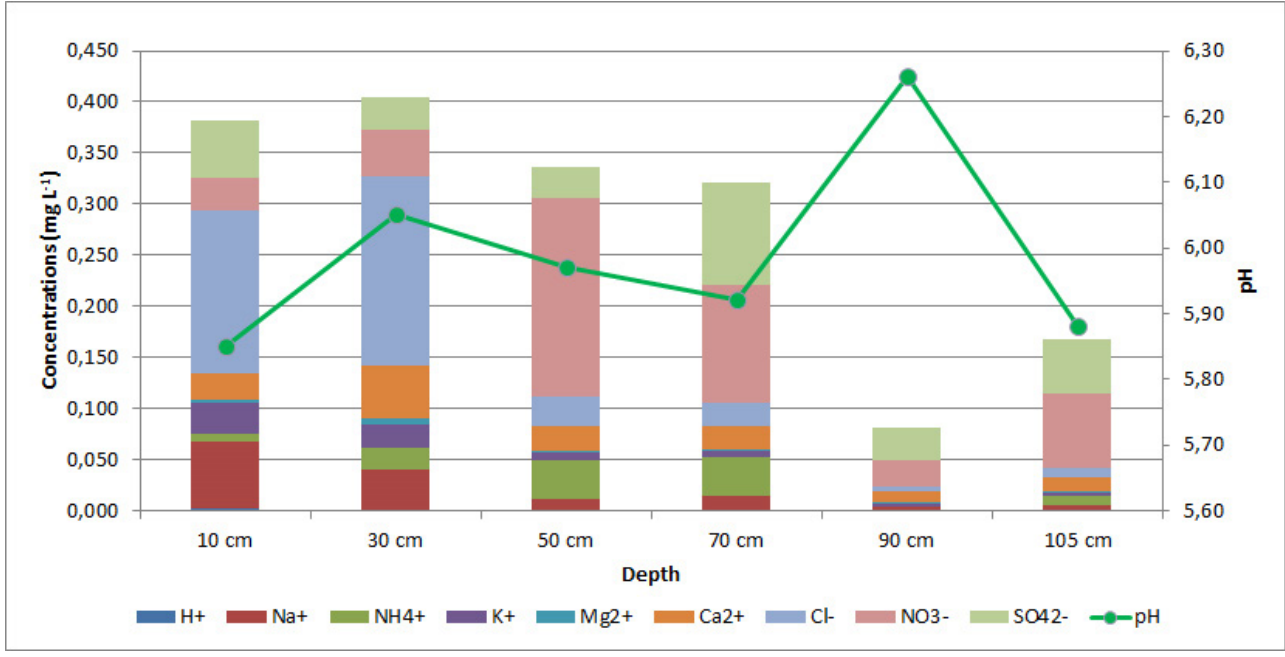

Fig.2. Snow chemical composition (concentration of major ions) and $\mathrm{pH}$ in the snow pit 